\title{
Factors Associated with Types and Intensity of Postoperative Pain following Gynecological Laparoscopic Surgery: A Cross-Sectional Study
}

\author{
Chia-Fen Hsien,' Chiu-Lin Wang, ${ }^{1,2}$ Cheng-Yu Long, ${ }^{2}$ Yung-Hung Chen, ${ }^{1}$ \\ Winter Yu-Ning Lee, ${ }^{1}$ Shih-Chin Chen, ${ }^{1}$ Kun-Ling Lin, ${ }^{2}$ Cherng-Jye Jeng, ${ }^{2}$ \\ Eing-Mei Tsai, ${ }^{2,3}$ and Feng-Hsiang Tang ${ }^{2,4}$ \\ ${ }^{1}$ Department of Obstetrics and Gynecology, Kaohsiung Municipal Siaogang Hospital, Kaohsiung Medical University, \\ Kaohsiung, Taiwan \\ ${ }^{2}$ Department of Obstetrics and Gynecology, Kaohsiung Medical University Hospital, Kaohsiung Medical University, Kaohsiung, Taiwan \\ ${ }^{3}$ Graduate Institute of Medicine, College of Medicine, Kaohsiung Medical University, Kaohsiung, Taiwan \\ ${ }^{4}$ Graduate Institute of Clinical Medicine, College of Medicine, Kaohsiung Medical University, Kaohsiung, Taiwan
}

Correspondence should be addressed to Feng-Hsiang Tang; tangfs88@gmail.com

Received 16 November 2016; Revised 17 July 2017; Accepted 7 August 2017; Published 13 September 2017

Academic Editor: Andrea Tinelli

Copyright (c) 2017 Chia-Fen Hsien et al. This is an open access article distributed under the Creative Commons Attribution License, which permits unrestricted use, distribution, and reproduction in any medium, provided the original work is properly cited.

\begin{abstract}
Objective. To evaluate influences of various factors on the types and intensity of postoperative pain following gynecologic laparoscopic surgery. Study Design. Cross-sectional questionnaire and chart review. Results. A total of 84 questionnaires were distributed and returned. The types of postlaparoscopic pain are different in multiparous women and nulliparous ones (71.43\% surgical wound pain versus $63.64 \%$ nonsurgical wound pain, $p=0.0033$ ) and those with striae gravidarum and without striae gravidarum (93.94\% surgical wound pain versus $52.94 \%$ nonsurgical wound pain, $p<0.0001$ ). On postoperative day 1 , the average VAS score is higher in nonsurgical wound pain than in surgical wound pain $(5.62 \pm 1.50$ versus $3.51 \pm 1.68, p<0.0001)$. The $\mathrm{CO}_{2}$ removal procedure has a significant negative correlation with the VAS of nonsurgical wound pain (coefficient: -0.4339 , $p=0.0187$ ). Conclusion. Our study suggests that women with abdominal rigidity (nulliparous, no striae gravidarum) experience mainly nonsurgical wound pain, while women with abdominal wall laxity mostly experience surgical wound pain. The VAS score of nonsurgical wound pain is greater than surgical wound pain on postoperative day 1 . The $\mathrm{CO}_{2}$ removal procedure has negative correlation to the VAS score of nonsurgical wound pain on postoperative day 1.
\end{abstract}

\section{Introduction}

Ever since the beginning of the surgical history, surgeons have continued to make effort pursuing surgical techniques with minimal invasiveness, the intention of which is to minimize trauma and decrease the postoperative pain and shorten the length of hospital stay. The introduction of laparoscopic surgery is revolutionary in this aspect; with the recent advances in the laparoscopic surgical instruments and techniques, laparoscopic surgery can be employed to most surgically indicated patients in the gynecology field [1].

Compared to traditional surgeries, the postoperative discomforts are less in laparoscopic ones. Due to the limited space of the abdominal cavity, pneumoperitoneum is an essential and unique procedure in laparoscopic surgery. However, if the pneumoperitoneum condition is inappropriate, or the $\mathrm{CO}_{2}$ removal is not done sufficiently after operation, comorbidities often occur. Furthermore, if $\mathrm{CO}_{2}$ builds up below the diaphragm, it will cause irritation of the phrenic nerve, and subsequently results in shoulder pain. Sometimes, this kind of comorbidities may be more debilitating than the incisional wound pain [2-4]. According to the previous studies, the percentage of patients that suffered from postlaparoscopic shoulder pain is in the range of $35 \%$ $\sim 80 \%$. The severity from mild to severe has all been reported, 


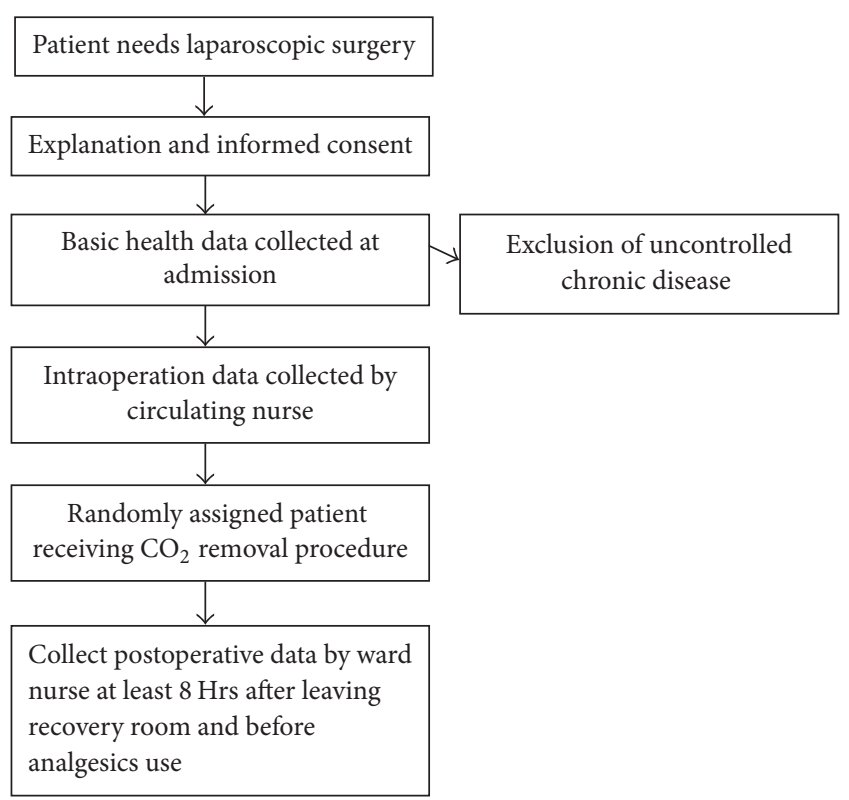

FIGURE 1: Flowchart of patient selection and enrollment.

and the duration of the discomfort may last up to 72 hours after operation $[5,6]$.

To the best of our knowledge, most of the investigations pertaining to the comorbidities of laparoscopy focus on the surgical complications mainly, such as intestinal trauma, ureter trauma, inferior vena cava compression and injury, and intraoperative $\mathrm{CO}_{2}$ temperature/moisture in association to postoperative pain $[7,8]$. Studies focused on the factors and the different factors in association with postoperative pain are currently limited in the literature. Thus, we designed this study to observe the factors which would have relationship to the different types and intensity of postlaparoscopic pain.

\section{Materials and Methods}

This is a cross-sectional study of the relationship between the different factors of laparoscopic gynecologic surgery and the resulting postoperative pain. Subjects who underwent gynecological laparoscopic surgery due to benign gynecologic condition in Kaohsiung Municipal Siaogang Hospital from January 01, 2011, to December 31, 2011, were included. But those who received other surgery at the same time (e.g., tension-free vaginal tape) were excluded from this study. All of the study subjects were capable of communicating effectively with Mandarin and/or Taiwanese, and the study participants' consent was obtained after the subjects were fully informed of the purpose of the study. The flowchart of patient selection and study is shown in Figure 1.

All the laparoscopic surgeries were performed via three trocars insertions, one $10 \mathrm{~mm}$ trocar inserted through umbilicus and the other two $5 \mathrm{~mm}$ trocars inserted through left lower quadrant of patient's abdomen. After completion of surgery, the 84 patients randomly received $\mathrm{CO}_{2}$ removal process by suction of intra-abdominal $\mathrm{CO}_{2}$ from $10 \mathrm{~mm}$ trocars till the abdominal wall is flat and soft. Other patients who do not receive this procedure would let the intraabdominal $\mathrm{CO}_{2}$ passively flow out from the $10 \mathrm{~mm}$ trocar. The two $5 \mathrm{~mm}$ trocars were removed before both steps.

The pre- and postmedication of anesthesia are according to the anesthesiologist decision. The analgesic drugs used in perianesthetic period are decided by anesthesiologist. We do not include those who use patient-controlled analgesia machine. We do not use local anesthesia agent before trocar insertion or removal. No special medication was used before insufflation of $\mathrm{CO}_{2}$.

In this cross-sectional study, data collection is via chart review and structured nondisguised questionnaires, which included the following:

(1) Demographic data: age, parity, height, weight, body surface area, and presence of striae gravidarum or not.

(2) Surgical parameters: volume of $\mathrm{CO}_{2}$ insufflated, preset intra-abdominal pressure, duration of the operation, postoperative $\mathrm{CO}_{2}$ removal, volume irrigated during operation, postoperative drainage placement, and laparoscopy procedure performed.

(3) Postoperative pain evaluation: includes the types and the intensity of the pain, which is assessed via the visual analogue scale (VAS). The types of postoperative pain are divided into surgical wound pain and nonsurgical wound pain. Nonsurgical wound pain is defined as any postoperative pain not located on the incisional trocar site, such as shoulder, intercostal, epigastric, and subphrenic area.

The demographic data was recorded by ward nursing staff on patient's admission. The presence of striae gravidarum or not and the surgical parameters were recorded by circulating nurse of operating room during operation. The postoperative pain evaluation was recorded by ward nursing staff using questionnaires on the morning of postoperative day 1 , and at least 8 hours after patient's returning to ward, but before any forms of analgesics are used after leaving recovery room. A total of 84 questionnaires were distributed and 84 questionnaires were answered and returned. The effective questionnaire return-ratio is thus $100 \%$.

The returned questionnaires were first encoded and then filled with the Excel program. Statistical analysis was performed with the application of the SPSS10.0 software (IBM). Statistical parameters analyzed included the mean, standard deviation, $t$ value, Chi-square test, and Pearson correlation.

\section{Results}

A total of 84 subjects who underwent gynecologic laparoscopy surgery were included in this study. Their demographic distributions and the various parameters were shown in Table 1 . The mean age of the patient is $40.10( \pm 11.34)$ years. The parity condition of those patient is 0 parities in $26.2 \%, 1 \sim 2$ parities in $48.8 \%$, and 3 parities or more in $25 \%$. The presence of striae gravidarum on the abdominal skin is observed in $39.3 \%$. The mean BMI is $24.41 \mathrm{~kg} / \mathrm{M}^{2}( \pm 4.87)$. The mean volume of $\mathrm{CO}_{2}$ insufflated during surgery is 204.54 liters $( \pm 165.11)$. Mean setting of intra-abdominal pressure 
TABLE 1: Demographic distributions and the various parameters.

\begin{tabular}{|c|c|c|c|c|c|c|}
\hline & Case number (percentage) & Average & Standard deviation & Maxi. & Mean & Mini. \\
\hline Age (years) & 84 & 40.10 & 11.34 & 81 & 39.5 & 17 \\
\hline $\mathrm{BMI}\left(\mathrm{Kg} / \mathrm{M}^{2}\right)$ & 84 & 24.41 & 4.87 & 37.96 & 22.9 & 16.7 \\
\hline Body surface area & 84 & 1.65 & 0.21 & 2.26 & 1.62 & 1.3 \\
\hline \multicolumn{7}{|l|}{ Parity } \\
\hline 0 & $22(26.2 \%)$ & & & & & \\
\hline $1-2$ & $41(48.8 \%)$ & & & & & \\
\hline$\geq 3$ & $21(25.0 \%)$ & & & & & \\
\hline \multicolumn{7}{|l|}{ Striae gravidarum } \\
\hline No & $51(60.7 \%)$ & & & & & \\
\hline Yes & $33(39.3 \%)$ & & & & & \\
\hline $\mathrm{CO}_{2}$ volume $(\mathrm{L})$ & & 204.54 & 165.11 & 878 & 154.9 & 33.7 \\
\hline Abdominal pressure $(\mathrm{mmHg})$ & & 14.77 & 0.700 & 18 & 15 & 12 \\
\hline Irrigation volume (mL) & & 1272.32 & 821.45 & 4500 & 1000 & 75 \\
\hline Blood loss (mL) & & 86.79 & 139.10 & 1050 & 50 & 5 \\
\hline Duration of surgery (hours) & & 1.66 & 0.71 & 4.583 & 1.583 & 0.333 \\
\hline \multicolumn{7}{|l|}{ Drainage placement } \\
\hline No & $83(98.8 \%)$ & & & & & \\
\hline Yes & $1(1.2 \%)$ & & & & & \\
\hline
\end{tabular}

is $14.77 \mathrm{mmHg}( \pm 0.7)$. Mean intra-abdominal irrigation (warmed normal saline) volume during operation is 1272.32 liters $( \pm 821.45)$. Average intraoperative blood loss is $86.79 \mathrm{ml}$ $( \pm 139.10)$. Mean body surface area is $1.65 \mathrm{M}^{2}( \pm 0.21)$. Mean operation time is 1.66 hours $( \pm 0.71)$.

The types of operation received by the 84 patients and the associated demographic data and factors were shown in Table 2. In LAVH group, the age and blood loss amount are significantly more than the adnexa surgery group. In laparoscopic myomectomy (LM) group, the insufflating $\mathrm{CO}_{2}$ volume is significantly more than the LAVH group, and the operation time is longer than all other three groups. There are no perioperative complications noted in those 84 patients included. The average VAS scores within different types of operation are not significantly different $(p=0.658)$.

The relationship between various parameters and the types of the postoperative pain are listed in Table 3. According to our study, the nulliparous women experienced mainly nonsurgical wound pain (63.64\%), while the multiparous women mostly experienced surgical wound pain (71.43\%). The types of pain in the two groups reach significant difference $(p=$ 0.0033).

In patients with observed striae gravidarum on her abdominal skin, $93.93 \%$ of them experience surgical wound pain. On the contrary, $52.94 \%$ of subjects who have no observable striae gravidarum experienced nonsurgical wound pain. The different expression of postoperative pain between the two groups is statistically significant $(p<$ 0.0001). Other factors, including intraoperative irrigating volume, intraoperative blood loss, infused $\mathrm{CO}_{2}$ volume, patient's $\mathrm{BMI}$, and the use of $\mathrm{CO}_{2}$ removal procedure or not, show no significant influences on the types of postoperative pain.
Comparisons of different factors between surgical wound pain group and nonsurgical wound pain group are listed in Table 4 . The visual analogue scale (VAS) on postoperative day 1 is statistically significantly different between the two groups (3.51 versus 5.62, $p<0.0001$ ). However, in terms of the influences on the duration of the operation or the subject's body surface area in association with surgical or nonsurgical wound pain, neither achieved statistical significance.

The relationship of VAS and the different variables were analyzed via the Pearson correlation and shown in Table 5. The results in surgical wound pain group show that the VAS of the surgical wound pain is inversely correlated with the volume used for irrigation during operation and the intraabdominal pressure during operation. On the other hand, the VAS of the surgical wound pain is directly correlated with the duration of the operation and the postoperative $\mathrm{CO}_{2}$ removal procedure. But neither four factors reach statistical significance.

The VAS of nonsurgical wound pain is directly correlated with intraoperative irrigation volume and intra-abdominal pressure during operation; but operation time is inversely correlated with it. All three factors do not reach significance statistically. Finally, the postoperative $\mathrm{CO}_{2}$ removal procedure has significant negative influence on the VAS score of postoperative nonsurgical wound pain.

\section{Conclusion}

Traditionally, postoperative pain is always a big issue for discussion and management. Since the development of laparoscopic surgery, the intensity of postoperative pain had decreased significantly when compared to laparotomy surgery [9]. But due to pneumoperitoneum during laparoscopic surgery, new types of postoperative pain become 
TABLE 2: Demographic data and factors of different types of operation.

\begin{tabular}{|c|c|c|c|c|c|}
\hline \multirow[t]{2}{*}{ Characteristics } & $\begin{array}{r}\text { LAVH (1) } \\
(N=29)\end{array}$ & $\begin{array}{l}\text { Adnexa (2) } \\
(N=24)\end{array}$ & $\begin{array}{c}\text { Myomectomy } \\
(3) \\
(N=12)\end{array}$ & $\begin{array}{l}\text { Others }(4)^{*} \\
(N=19)\end{array}$ & \multirow[t]{2}{*}{$p$ value } \\
\hline & Mean \pm SD & Mean \pm SD & Mean \pm SD & Mean \pm SD & \\
\hline Mean age (years) & $43.76 \pm 6.10$ & $34.63 \pm 14.99$ & $39.00 \pm 7.73$ & $42.11 \pm 12.38$ & $0.022(\mathrm{a})$ \\
\hline BMI & $25.90 \pm 5.53$ & $23.57 \pm 5.21$ & $24.18 \pm 3.91$ & $23.44 \pm 3.54$ & 0.223 \\
\hline $\operatorname{BSA}\left(\mathrm{M}^{2}\right)$ & $1.68 \pm 0.19$ & $1.63 \pm 0.21$ & $1.66 \pm 0.19$ & $1.60 \pm 0.21$ & 0.493 \\
\hline \multicolumn{6}{|l|}{ Parity } \\
\hline 0 & $0(0.0 \%)$ & $12(50.0 \%)$ & $2(16.7 \%)$ & $8(42.1 \%)$ & \multirow[t]{3}{*}{0.001} \\
\hline $1-2$ & $5(45.5 \%)$ & $1(4.2 \%)$ & $3(25.0 \%)$ & $2(18.2 \%)$ & \\
\hline$\geq 3$ & $24(47.1 \%)$ & $11(45.8 \%)$ & $7(58.3 \%)$ & $9(17.6 \%)$ & \\
\hline \multicolumn{6}{|l|}{ Previous surgery } \\
\hline No & $18(62.07 \%)$ & $14(58.33 \%)$ & $10(83.33 \%)$ & $11(57.89 \%)$ & \multirow[t]{2}{*}{0.461} \\
\hline Yes & $11(37.93 \%)$ & $10(41.67 \%)$ & $2(16.67 \%)$ & $8(42.11 \%)$ & \\
\hline \multicolumn{6}{|l|}{ Striae gravidarum } \\
\hline No & $14(48.3 \%)$ & $17(70.8 \%)$ & $8(66.7 \%)$ & $12(63.2 \%)$ & \multirow[t]{2}{*}{0.371} \\
\hline Yes & $15(51.7 \%)$ & $7(29.2 \%)$ & $4(12.1 \%)$ & $7(36.8 \%)$ & \\
\hline $\mathrm{CO}_{2}$ volume $(\mathrm{ml})$ & $184.19 \pm 131.57$ & $128.5 \pm 55.48$ & $401.17 \pm 253.37$ & $213.61 \pm 148.16$ & $<0.001(\mathrm{~b})$ \\
\hline Mean intra-abdominal pressure $(\mathrm{mmHg})$ & $14.72 \pm 0.53$ & $14.92 \pm 0.93$ & $14.67 \pm 0.49$ & $14.72 \pm 0.75$ & 0.695 \\
\hline Irrigation volume $(\mathrm{ml})$ & $1316.38 \pm 825.55$ & $1358.33 \pm 686.46$ & $866.67 \pm 619.87$ & $\begin{array}{c}1377.78 \pm \\
1065.81\end{array}$ & 0.331 \\
\hline Intraoperative blood loss Volume (ml) & $161.55 \pm 202.06$ & $25.42 \pm 30.29$ & $76.25 \pm 86.74$ & $54.44 \pm 71.12$ & $0.002(\mathrm{a})$ \\
\hline Duration of surgery (hours) & $1.84 \pm 0.49$ & $1.12 \pm 0.38$ & $2.42 \pm 0.84$ & $1.52 \pm 0.62$ & $<0.001(\mathrm{c})$ \\
\hline Average VAS score & $1.30 \pm 0.12$ & $1.11 \pm 0.14$ & $1.08 \pm 0.19$ & $1.13 \pm 0.15$ & 0.658 \\
\hline
\end{tabular}

* Patients who received adhesiolysis at the same time were included in this group; (a) (1) > (2); (b) (3) > (1); (c) (3) > (1), (3), (4).

predominant [10]. There are many researches focused on how to prevent or deal with the nonsurgical wound pain after laparoscopic surgery $[11,12]$. But few studies focused on the factors associated with it. In our study, we try to evaluate different factors associated with the two types of postoperative pain, namely, surgical wound pain and nonsurgical wound pain.

The primary result shows that there is a significant difference in the types of postoperative pain in association with the parity. With those who had no childbearing before, the mainly recorded types of postoperative pain are nonsurgical wound pain. With those who had parity before, irrespective of parity number, surgical wound pain is the main type of postoperative pain. Besides, patient with striae gravidarum had a $93.94 \%$ ratio whose postoperative pain is surgical wound pain type. When comparing to the result in those women without striae gravidarum, the type of postoperative pain is significantly different. While other factors, including intraoperative irrigating volume, intraoperative blood loss, infused $\mathrm{CO}_{2}$ volume, patient's $\mathrm{BMI}$, and the use of $\mathrm{CO}_{2}$ removal procedure or not, show no significant influences on the types of postoperative pain. According to our study, it is suggested that the degree of abdominal wall laxity is an important factor to influence the type of postoperative pain. In theory, we believe that nonsurgical wound pain results from distension and irritation to the peritoneum, which result in release of inflammatory substances that stimulate the nociceptors of nerve endings [13]. It is reasonable that in patient with abdominal wall laxity like multiparity or presence of striae gravidarum, there is less stretching and irritation to the peritoneum in the same condition comparing to those whose abdominal wall is more rigid when receiving laparoscopic surgery.

According to our study, patients who suffered from nonsurgical wound pain (e.g., shoulder and epigastric pain) have a higher VAS score compared to those who suffered from surgical wound pain $(5.62$ versus $3.51, p<0.0001)$. The need of the pneumoperitoneum procedure with $\mathrm{CO}_{2}$ insufflation results in the postoperative hyperstimulation of the diaphragm and the phrenic nerve, the result of which is pain and soreness in nonsurgical sites, such as in the shoulders and epigastric region, causing great discomfort and inconvenience to the patient $[14,15]$. But the reason why the degree of nonsurgical wound pain is higher than the surgical wound pain is unknown. Since our study shows that the abdominal wall laxity is an important factor affecting the type of postoperative pain, we believe that those who suffered from nonsurgical wound pain mostly did not experience abdominal wall distension before and have more rigid abdominal wall. So the score of VAS on the postoperative day 1 would be interpreted higher in the nonsurgical wound pain group.

Since the introduction of laparoscopic surgery, there are many researches on the methods to reduce the intensity of nonsurgical wound pain. Generally, reducing $\mathrm{CO}_{2}$ retention 
TABLE 3: Types of the postoperative pain.

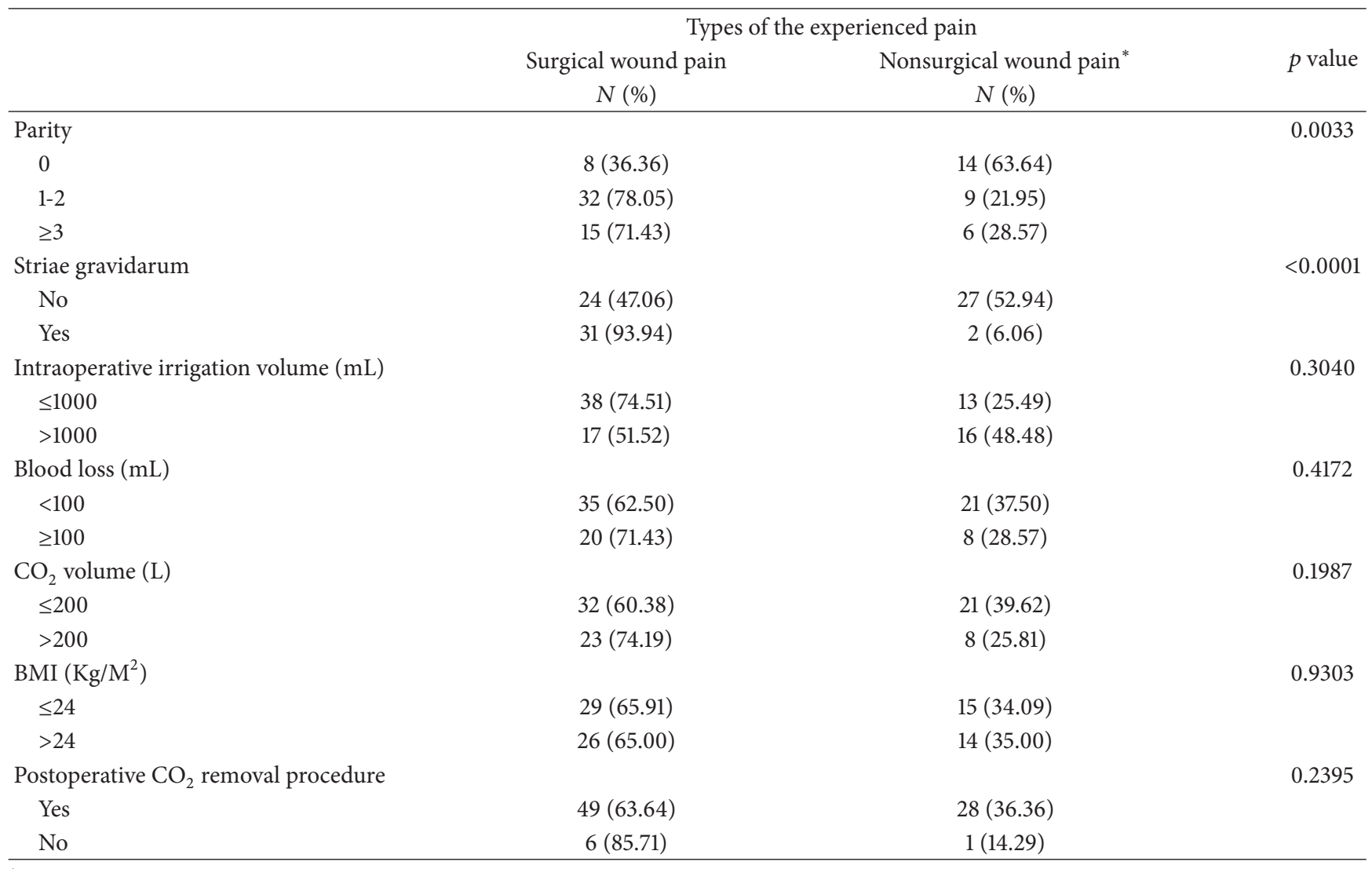

${ }^{*}$ Nonsurgic wound pain includes shoulder pain, intercostal pain, and epigastric pain.

TABLE 4: Comparisons of different types of postoperative pain.

\begin{tabular}{|c|c|c|c|}
\hline & Case number (\%) & Mean \pm SD & $p$ value \\
\hline Postoperative day 1 (VAS) & & & $<0.0001$ \\
\hline Surgical wound & $55(65.48)$ & $3.51 \pm 1.68$ & \\
\hline Nonsurgical wound & $29(34.52)$ & $5.62 \pm 1.50$ & \\
\hline Duration of the operation (hr.) & & & 0.8982 \\
\hline Surgical wound & $55(65.48)$ & $1.65 \pm 0.74$ & \\
\hline Nonsurgical wound & $29(34.52)$ & $1.67 \pm 0.65$ & \\
\hline BSA & & & 0.6178 \\
\hline Surgical wound & $55(65.48)$ & $1.64 \pm 0.20$ & \\
\hline Nonsurgical wound & $29(34.52)$ & $1.67 \pm 0.23$ & \\
\hline
\end{tabular}

and decreasing phrenic nerve stimulation by materials are the two main methods. According to the study by Tsai et al. [16], postoperative intra-abdominal injection of $25 \sim 30 \mathrm{~mL} / \mathrm{kg}$ of normal saline solution may facilitate the removal of intraabdominal $\mathrm{CO}_{2}$ gas, resulting in a $40.7 \%$ reduction of the ratio of patients suffering from shoulder discomfort and epigastric pain (24 hours after operation) [11, 17]. Phelps et al. [3] also reported that $\mathrm{CO}_{2}$ removal by means of pulmonary recruitment maneuver and Trendelenburg position may successfully reduce postlaparoscopic shoulder pain cases to $20 \%$. In our study, we also show that the $\mathrm{CO}_{2}$ removal procedure has significantly negative correlation to the VAS score of nonsurgical wound pain on postoperative day 1.
To the best of our knowledge, this study is the first of a few studies on the different factors associated with different types of postoperative pain after laparoscopic gynecologic surgery, which shows that in patient with more rigid abdominal wall, there is more possibility that she will experience nonsurgical wound pain after laparoscopic surgery and that the pain will be more intense. However, $\mathrm{CO}_{2}$ removal procedure may have benefit on it. On the other hand, in patient who are multiparous or have striae gravidarum on the abdominal skin, prevention or management of postoperative surgical wound pain may be important. There are limitations to our study, the sample size is not so large, so we cannot observe those factors in just one type of operation, for example, in 
TABLE 5: Correlations of VAS score and intraoperative factors.

(a) Surgical wound pain

\begin{tabular}{lccc}
\hline Variable 1 & Variable 2 & Correlation coefficient & $p$ value \\
\hline Intraoperative irrigation volume & VAS & -0.0656 & 0.6343 \\
Intra-abdominal pressure & VAS & -0.2443 & 0.0722 \\
$\mathrm{CO}_{2}$ removal procedure & VAS & 0.2046 & 0.1341 \\
Operation time & VAS & 0.0949 & 0.4909 \\
\hline
\end{tabular}

(b) Nonsurgical wound pain

\begin{tabular}{lccc}
\hline Variable 1 & Variable 2 & Correlation coefficient & $p$ value \\
\hline Intraoperative irrigation volume & VAS & 0.1588 & 0.4105 \\
Intra-abdominal pressure & VAS & 0.1262 & 0.5143 \\
$\mathrm{CO}_{2}$ removal & VAS & -0.4339 & 0.0187 \\
Operation time & VAS & -0.0618 & 0.7502 \\
\hline
\end{tabular}

LAVH. The different operation type may have influence on the result. Besides, VAS score is a subjective indicator, which may be not so precisely described by patient. Further study on it may help us to clarify the mechanism of postoperative pain after laparoscopic gynecologic surgery and develop more effective methods to reduce the intensity of pain in different types in patient receiving gynecologic laparoscopic surgery.

\section{Conflicts of Interest}

The authors declare that there are no conflicts of interest regarding the publication of this paper.

\section{References}

[1] D. Dargent, X. Martin, A. Sacchetoni, and P. Mathevet, "Laparoscopic vaginal radical trachelectomy: a treatment to preserve the fertility of cervical carcinoma patients," Cancer, vol. 88, no. 8, pp. 1877-1882, 2000.

[2] H.-Y. Shin, S.-H. Kim, Y.-J. Lee, and D.-K. Kim, "The effect of mechanical ventilation tidal volume during pneumoperitoneum on shoulder pain after a laparoscopic appendectomy," Surgical Endoscopy and Other Interventional Techniques, vol. 24, no. 8, pp. 2002-2007, 2010.

[3] P. Phelps, O. S. Cakmakkaya, C. C. Apfel, and O. C. Radke, "A simple clinical maneuver to reduce laparoscopy-induced shoulder pain: a randomized controlled trial," Obstetrics Gynecology, vol. 111, no. 5, pp. 1155-1160, 2008.

[4] K. Slim, J. Bousquet, F. Kwiatkowski, G. Lescure, D. Pezet, and J. Chipponi, "Effect of $\mathrm{CO}_{2}$ gas warming on pain after laparoscopic surgery: a randomized double-blind controlled trial," Surgical Endoscopy, vol. 13, no. 11, pp. 1110-1114, 1999.

[5] J. B. Dixon, Y. Reuben, C. Halket, and P. E. O'Brien, "Shoulder pain is a common problem following laparoscopic adjustable gastric band surgery," Obesity Surgery, vol. 15, no. 8, pp. 1111-1117, 2005.

[6] S. I. Jabbour-Khoury, A. S. Dabbous, F. J. Gerges, M. S. Azar, C. M. Ayoub, and G. S. Khoury, "Intraperitoneal and intravenous routes for pain relief in laparoscopic cholecystectomy," JSLS : Journal of the Society of Laparoendoscopic Surgeons / Society of Laparoendoscopic Surgeons, vol. 9, no. 3, pp. 316-321, 2005.
[7] O. Donnez, P. Jadoul, J. Squifflet, and J. Donnez, "A series of 3190 laparoscopic hysterectomies for benign disease from 1990 to 2006: Evaluation of complications compared with vaginal and abdominal procedures," BJOG: An International Journal of Obstetrics and Gynaecology, vol. 116, no. 4, pp. 492-500, 2009.

[8] J. Neudecker, S. Sauerland, and E. Neugebauer, “The European Association for Endoscopic Surgery clinical practice guideline on the pneumoperitoneum for laparoscopic surgery," Surgical Endoscopy and Other Interventional Techniques, vol. 16, no. 7, pp. 1121-1143, 2002.

[9] L. S. Campos, L. Francisco Limberger, A. Tetelbom Stein, and A. Nocchi Kalil, "Postoperative pain and perioperative outcomes after laparoscopic radical hysterectomy and abdominal radical hysterectomy in patients with early cervical cancer: a randomised controlled trial," Trials, vol. 14, no. 1, article 293, 2013.

[10] R. Vecchio, P. Murabito, and E. Panascia, "Postoperative pain in laparoscopic surgery," Il Gionale di Chirurgia, pp. 13-17, 2002.

[11] M. Barczyński and R. M. Herman, "Low-pressure pneumoperitoneum combined with intraperitoneal saline washout for reduction of pain after laparoscopic cholecystectomy: a prospective randomized study," Surgical Endoscopy and Other Interventional Techniques, vol. 18, no. 9, pp. 1368-1373, 2004.

[12] J. L. Marks, B. Ata, and T. Tulandi, "Systematic review and metaanalysis of intraperitoneal instillation of local anesthetics for reduction of pain after gynecologic laparoscopy," Journal of Minimally Invasive Gynecology, vol. 19, no. 5, pp. 545-553, 2012.

[13] W. G. Mouton, J. R. Bessell, K. T. Otten, and G. J. Maddern, "Pain after laparoscopy," Surgical Endoscopy, vol. 13, no. 5, pp. 445448, 1999.

[14] P. Mathevet, P. Valencia, C. Cousin, G. Mellier, and D. Dargent, "Operative injuries during vaginal hysterectomy," European Journal of Obstetrics Gynecology and Reproductive Biology, vol. 97, no. 1, pp. 71-75, 2001.

[15] C.-L. Lee, K.-G. Huang, S. Jain, C.-J. Wang, C.-F. Yen, and Y.-K. Soong, "A new portal for gynecologic laparoscopy," Journal of the American Association of Gynecologic Laparoscopists, vol. 8, no. 1, pp. 147-150, 2001.

[16] H.-W. Tsai, Y.-J. Chen, C.-M. Ho et al., "Maneuvers to decrease laparoscopy-induced shoulder and upper abdominal pain: a randomized controlled study," Archives of Surgery, vol. 146, no. 12, pp. 1360-1366, 2011. 
[17] M. E. Esmat, M. M. A. Elsebae, M. M. A. Nasr, and S. B. Elsebaie, "Combined low pressure pneumoperitoneum and intraperitoneal infusion of normal saline for reducing shoulder tip pain following laparoscopic cholecystectomy," World Journal of Surgery, vol. 30, no. 11, pp. 1969-1973, 2006. 


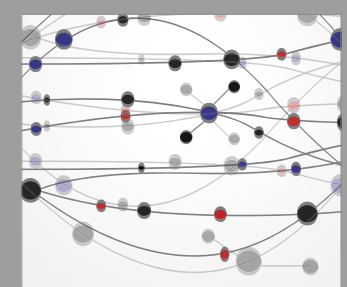

The Scientific World Journal
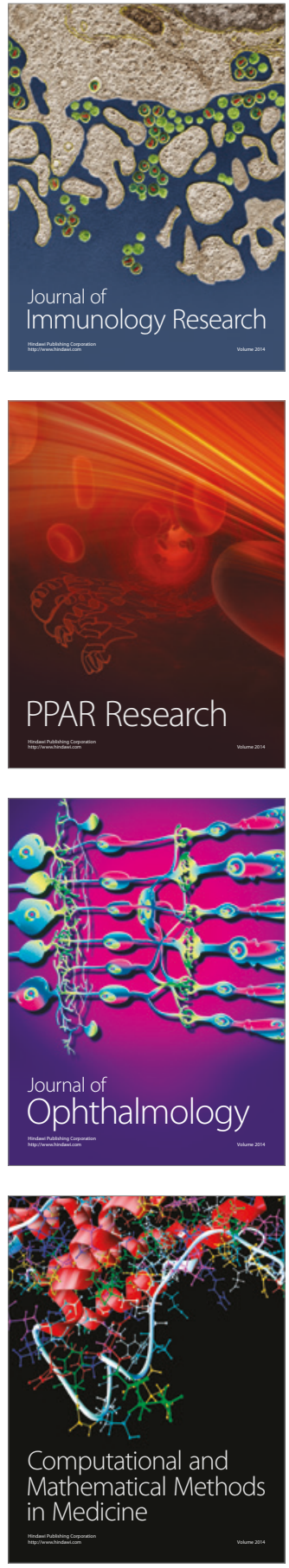

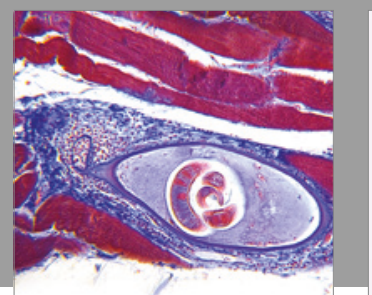

Gastroenterology Research and Practice
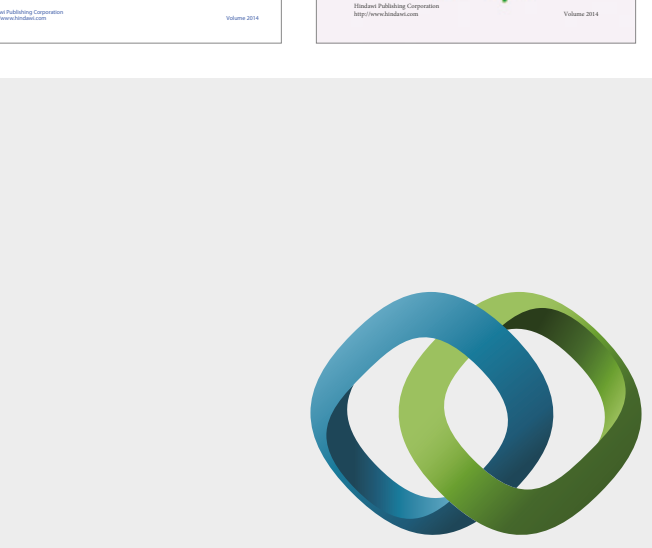

\section{Hindawi}

Submit your manuscripts at

https://www.hindawi.com
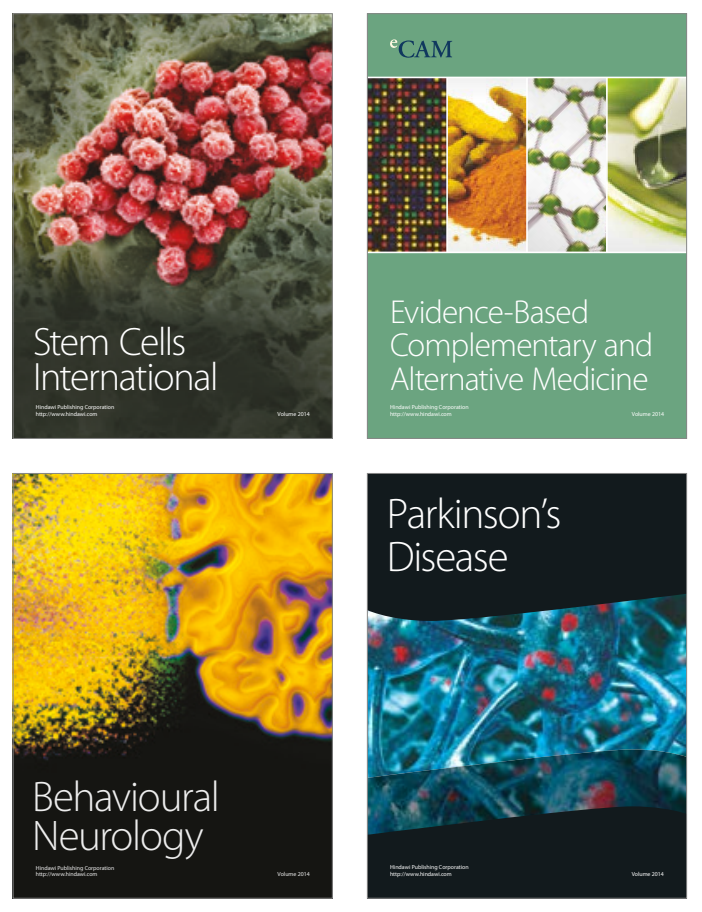
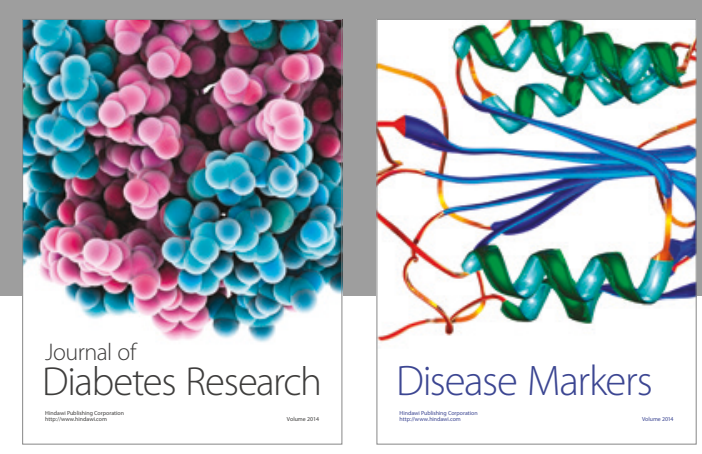

Disease Markers
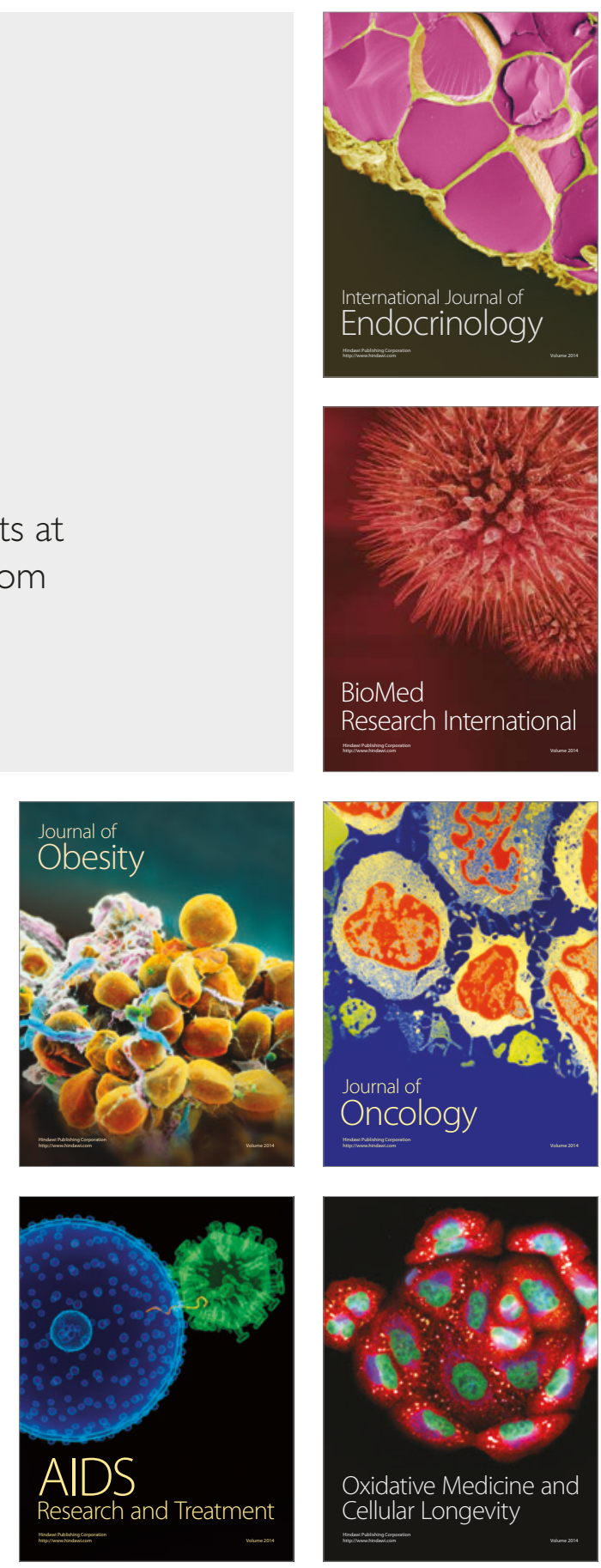